\title{
BORON TRIFLUORIDE PROMOTED REACTION OF DITHIO-SUBSTITUTED ALLYLIC ANIONS AND CYCLIC ETHERS
}

\author{
Jim-Min Fang ${ }^{*}$ and Ming-Yi Chen \\ Department of Chemistry, National Taiwan University \\ Taipei, 10764, Taiwan, Republic of China
}

Abstract-- Allylic anions generated from 2-propenyl-1,3-dithiane and 2-styryl-1,3-dithiane react exclusively at $\alpha$-carbons with three- to six-membered cyclic ethers in the presence of $\mathrm{BF}_{3} \cdot \mathrm{Et}_{2} \mathrm{O}$.

It has been shown that combination of organolithium and $\mathrm{BF}_{3} \cdot \mathrm{Et}_{2} \mathrm{O}$ is superb for the ring-opening reaction of oxiranes and oxetanes. ${ }^{1}$ With 2 -substituted oxirane, the ring-opening reaction occurs selectively at the less hindered site. The active species in the reaction of alkyllithium is once presumed to be $\mathrm{RC} \equiv \mathrm{C}-\mathrm{BF}_{3},{ }^{1}, 2$ although other evidence indicates the reaction may proceed via a coordinate intermediate of Lewis acid $\mathrm{BF}_{3}$ and cyclic cther, which is then attacked by alkyl- or vinyl- or phenyllithium. ${ }^{3}$ More recently, ring-opening reactions of tetrahydrofurans and tetrahydropyrans, most of them having phenyl group(s) at the $\mathrm{C}-2$ positions, are also realized by treatment with the mixed reagent of allyl- (or alkynyl-)silane and $\mathrm{TiCl}_{4} .^{4}$ Since the reaction occurs selectively at the more substituted $\mathrm{C}-2$ site, it may proceed via a cationic intermediate stabilized by phenyl group(s). This method is synthetically useful in extention of four and five carbon units, but it is not applicable to reactions with parent tetrahydrofuran, or tetrahydropyran, or their 2-alkyl derivatives. He here demonstrate effective ring-opening reactions of various cyclic ethers by allylic anions generated from 2-propenyl-1,3-dithiane ${ }^{5}$ and 2-styryl-1,3-dithiane ${ }^{6}$ (Scheme 1).

The typical experimental procedure is described as follows. To a solution of 2-propenyl-1,3-dithiane $(1 \mathrm{mmol})$ in ether $(10 \mathrm{~mL})$ was added dropwise $n$-BuLi $(1.2 \mathrm{mmol}, 1.6 \mathrm{M}$ in hexane) at $-40{ }^{\circ} \mathrm{C}$. After stirring for $20 \mathrm{~min}$, the resulting allyllithium solution was cooled to $-78{ }^{\circ} \mathrm{C}$, and $1 \mathrm{mmol}$ of $\mathrm{BF}_{3} . \mathrm{Et}_{2} \mathrm{O}$ (diluted with $1 \mathrm{~mL}$ of ether) was added dropwise, followed by addition of $1.2 \mathrm{mmol}$ of appropriate cyclic ether. The ring-opening reaction completed in 20 to 60 min as revealed by the TLC analysis.

The reaction is highly regioselective. As the hardness of cyclic ether greatly increases when it coordinates with $\mathrm{BF}_{3}$, it is expected to react at the $\alpha^{-}$site of dithio-substituted allylic anion. 7 In agreement with precedent, present ring-opening reactions took place exclusively at the less hindered $\alpha^{\prime}$-carbons of 2 -methyloxirane and 2 -methylfuran, 1 while " reactions with 2-phenyloxirane showed preference for attack at the benzyl position.4, ${ }_{8}$ This method provides a wide scope of carbon-carbon bond formation with both parent and substituted three- to six-membered cyclic ethers in giving high yields of alcohol products (3-18).9 As the dithiane moiety is readily hydrolyzed with $\mathrm{HgCl}_{2}$, this method also culminates in conversion of $\alpha, \beta$-unsaturated aldehydes to enones and related compounds by the polarity reversal

process. Thus, treatment of styryldithiane 6 with $\mathrm{HgCl}_{2}$ (aqueous $\mathrm{MeOH}, 8{ }^{\circ} \mathrm{C}, 0.5 \mathrm{~h}$ ) afforded 5-hydroxy-1-phenyl-1-hexen-3-one (19) as the sole product. Hydrolysis of 11 ( $\mathrm{HgCl}_{2}$, aqueous $\mathrm{MeOH})$ followed by demercuration $\left(\mathrm{NaOH}, \mathrm{NaBH}_{4}\right)^{10}$ resulted in a single product of ketone 20 . 
Scheme 1.

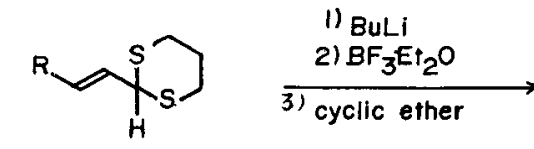

$$
\begin{array}{ll}
1 \mathrm{R} & =\mathrm{Me} \\
2 \mathrm{R} & =\mathrm{Ph}
\end{array}
$$

(a) The number in the parenthes is represents isolated yield $(\%)$ of products. (b) 9 is the $\gamma$-substitution product consisted of two diastereomers $(2: 1)$.

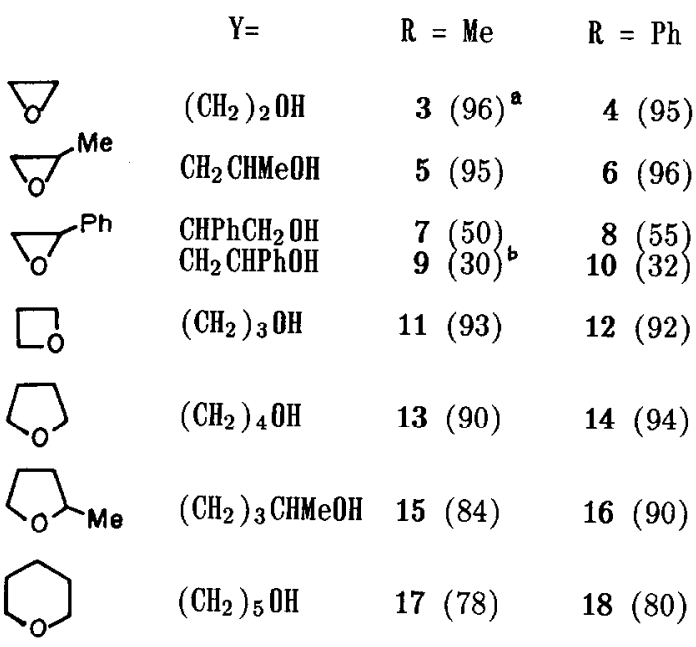<smiles>CC(C)C(CO)PC1=C2SCCCC2S1</smiles>

Similar reaction of propenyldithiane 12 in aqueous $\mathrm{CH}_{3} \mathrm{CN}$ gave dihydroxy ketone 21 in a high yield. When compound 3 was treated subsequently with $\mathrm{HgCl}_{2}, \mathrm{NaOH}$ and excess of $\mathrm{NaBH}_{4}$, a product of cis 2-methyl-4-hydroxytetrahydropyran (22) was obtained exclusively.<smiles>O=C(C=Cc1ccccc1)CC(O)[N+](=O)[O-]</smiles>

19

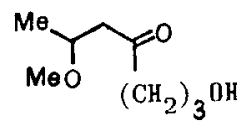

20

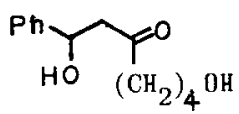

21<smiles>CC1CC(O)CCO1</smiles>

22

\section{References and Notes:}

1. (a) Yamaguchi, M.; Hirao, I. Tetrahedron Lett. 1983, 24, 391. (b) Yamaguchi, M.; Nobayashi, U.; Hirao, I. ibid. 1983, 24, 5121.

2. Volkmann, R. A.; Davis, J. T.; Meltz, C. N. J. Am. Chem. Soc. 1983, 105, 5946.

3. Eis, M. J.; Wrobel, J. E.; Ganem, B. ibid. 1984, 106, 3693. Similar mechanism is accounted for reactions of acetal and orthoester, see (a) Suzuki, M.; Yanagisawa, A.; Noyori, R.

Tetrahedron Lett. 1982, 23, 3595 and (b) Pelter, A.; Al-Bayati, R. ibid. 1982, 23, 5229.

4. 0ku, A.; Homoto, Y.; Harada, T. Chemistry Lett. 1986, 1495.

5. (a) Ziegler, F. E.; Mencel, J. J. Tetrahedron Lett. 1983, 24, 1859. (b) Fang, J. M.; Liao, L. F. ; Hong, B. C. J. Org. Chem. 1986, 51, 2828.

6. Murphy, W. S.; Wattanasin, S. J. Chem. Soc. Perkin Trans 1 1980, 2678.

7. (a) Fang, J. M.; Hong, B. C.; Liao, L. F. J. Org. Chem. 1987, 52, 855. (b) Fang, J. M.; Chen, M. Y.; Yang, W. J. the preceding manuscript.

8. (a) Node, M.; Nishide, K.; Fuji, K.; Fujita, E. J. Org. Chem. 1980, 45, 4275. (b) 0ku, A.; Harada, T.; Kita, K. Tetrahedron Lett. 1982, 29, 681.

9. All products had satisfactory elemental anlalyses and compatible spectra (IR, MS and NMR).

10. Brown, H. C.; Geoghegan, Jr, P. J. J. Org. Chem. 1970, 35, 1844. 